05

\title{
Особенности высокоскоростного проникания ударника из пористого сплава на основе вольфрама с упрочняющим наполнителем в стальную преграду
}

\author{
(C) А.Н. Ищенко, С.А. Афранасьева , Н.Н. Белов, В.В. Буркин, \\ К.С. Рогаев, А.Ю. Саммель, А.Б. Скосырский, \\ А.Н. Табаченко, Н.Т. Югов
}

Научно-исследовательский институт прикладной математики и механики Национального исследовательского Томского государственного университета

๑ E-mail: s.a.afanasyeva@mail.ru

Поступило в Редакцию 23 февраля 2017 г.

Рассматривается комплексная проблема увеличения проникающей способности ударников из высокопористых композитов на основе вольфрама путем улучшения их прочностных свойств легированием упрочняющими компонентами в условиях высокоскоростного соударения. Методом жидкофазного спекания разработаны образцы ударников на основе пористого сплава ВНЖК (вольфрам + никель + железо + кобальт), легированного карбидом вольфрама с кобальтом ВК8 и карбидом титана-вольфрама TiWC. Проведены динамические испытания ударников из разработанных сплавов при скорости соударения со стальной преградой порядка $2800 \mathrm{~m} / \mathrm{s}$. Глубина проникания ударника из пористого сплава ВНЖК, легированного карбидами вольфрама, превышает более чем на $30 \%$ глубину проникания ударника из монолитного сплава ВНЖ-90 (вольфрам + никель + железо с содержанием вольфрама 90\%).

DOI: 10.21883/PJTF.2017.17.44945.16755

Одним из основных направлений повышения проникающей способности инертных металлических ударников в металлические преграды является использование для их изготовления материалов с более совершенным комплексом физико-механических свойств, а также увеличение скорости соударения.

В последнее время наблюдается возрастающий интерес к исследованию высокоскоростного удара [1,2]. Ранее [3] был установлен феномен 
аномально глубокого проникания ударника из стальных опилок в стальную преграду по сравнению с прониканием равного по массе и диаметру монолитного стального ударника при скорости удара $3.69 \mathrm{~km} / \mathrm{s}$. Дальнейшие исследования [4] показали устойчивое увеличение глубины проникания ударников из пористых материалов с матрицей из стали и сплава ВНЖ-90 (сплав вольфрам + никель + железо с содержанием вольфрама 90\%) в полубесконечную стальную мишень с увеличением пористости и скорости соударения начиная с $1.8-2 \mathrm{~km} / \mathrm{s}$, что подтолкнуло к созданию композиционных пористых материалов на основе высокопрочных сплавов [5]. Однако наличие высокой пористости материала делает ударник малопригодным для высокоскоростного метания из-за невысокой прочности [6]. С увеличением нагрузки при разгоне ударник в канале ствола может разрушиться. Следовательно, наряду с улучшением прочностных характеристик композиционных пористых материалов необходимо решать проблему оптимального разгона метаемых тел в баллистической установке до высоких скоростей в щадящем режиме нагрузок на метаемое тело.

К настоящему времени разработаны баллистические установки на основе ствольно-реактивной технологии метания [7,8], функционирующие в артиллерийском диапазоне давлений (до $\sim 600 \mathrm{MPa}$ ) и позволяющие реализовать уровень скоростей ударников массой $30-50 \mathrm{~g}$ до $3 \mathrm{~km} / \mathrm{s}$, обеспечивая при этом постепенное нарастание нагрузки в канале ствола.

Задача данного исследования - разработка композиционных материалов на основе высокопористого вольфрамового сплава, обладающих повышенными проникающей способностью и прочностью в условиях высокоскоростного соударения с металлическими преградами.

Одним из возможных путей повышения прочности пористых сплавов на основе сплава ВНЖК (вольфрам + никель + железо + кобальт) является их легирование высокопрочными компонентами типа карбидов вольфрама. С этой целью методом высокотемпературного спекания в вакуумной печи получены образцы ударников на основе пористого сплава ВНЖК, легированного карбидом вольфрама с кобальтом ВК8 (сплав ВНЖК + ВК8) при различном содержании последнего: 20, 30, 40, 60, 70 wt.\%. Исходная плотность сплава ВНЖК составляет $\rho_{0}=16.25 \mathrm{~g} / \mathrm{cm}^{3}$, ВК $8-\rho_{0}=14.76 \mathrm{~g} / \mathrm{cm}^{3}$.

Как показано на рис. 1, влияние содержания ВК8 на плотность композита ВНЖК + ВК8 не аддитивно при сплавообразовании исходных

Письма в ЖТФ, 2017, том 43, вып. 17 


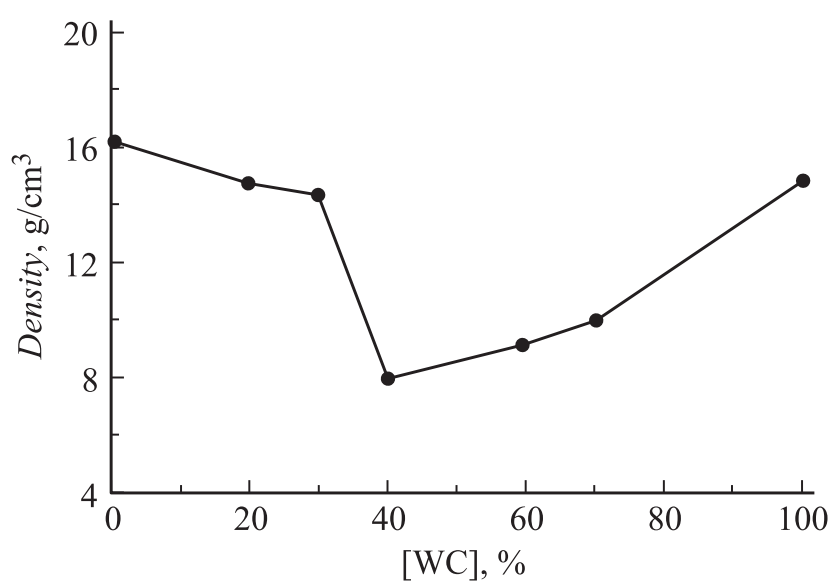

Рис. 1. Влияние содержания ВК 8 на плотность композиционного материала ВНЖК + ВК8.

компонентов. Видно, что повышение содержания ВК8 в сплаве с ВНЖК приводит сначала к резкому понижению плотности, а затем к ее повышению.

Исследования структуры изломов полученных сплавов после испытания образцов на разрыв (рис. 2) свидетельствуют о том, что в результате высокотемпературного спекания понижение плотности может быть объяснено повышением пористости этих сплавов.

Видно, что составы ВНЖК + ВК8 имеют развитую пористость, зависящую от состава компонентов. Наибольшей пористостью отличается состав, содержащий 40 wt.\% ВК8 (ВНЖК + 40 wt.\% ВК8) (рис. 2,a). Размер частиц в зависимости от состава также меняется. Для состава ВНЖК + 40 wt.\% ВК8 характерна мелкая разветвленная сотовая структура с размером частиц порядка $1 \mu \mathrm{m}$. Отличительной особенностью структуры состава ВНЖК + 70wt.\% ВК8 является то, что частицы обладают острыми краями (рис. $2, b$ ), их размер составляет $1-4 \mu \mathrm{m}$.

Для сравнения глубины проникания $h$ ударников в стальную преграду изготовлены экспериментальные образцы с одинаковыми массой $m=30 \mathrm{~g}$ и диаметром $d=9 \mathrm{~mm}$ : ударник из сплава ВНЖК +70 wt. $\%$ ВК8 плотностью $\rho_{0}=10.29 \mathrm{~g} / \mathrm{cm}^{3}$ и ударник из сплава

Письма в ЖТФ, 2017, том 43, вып. 17 

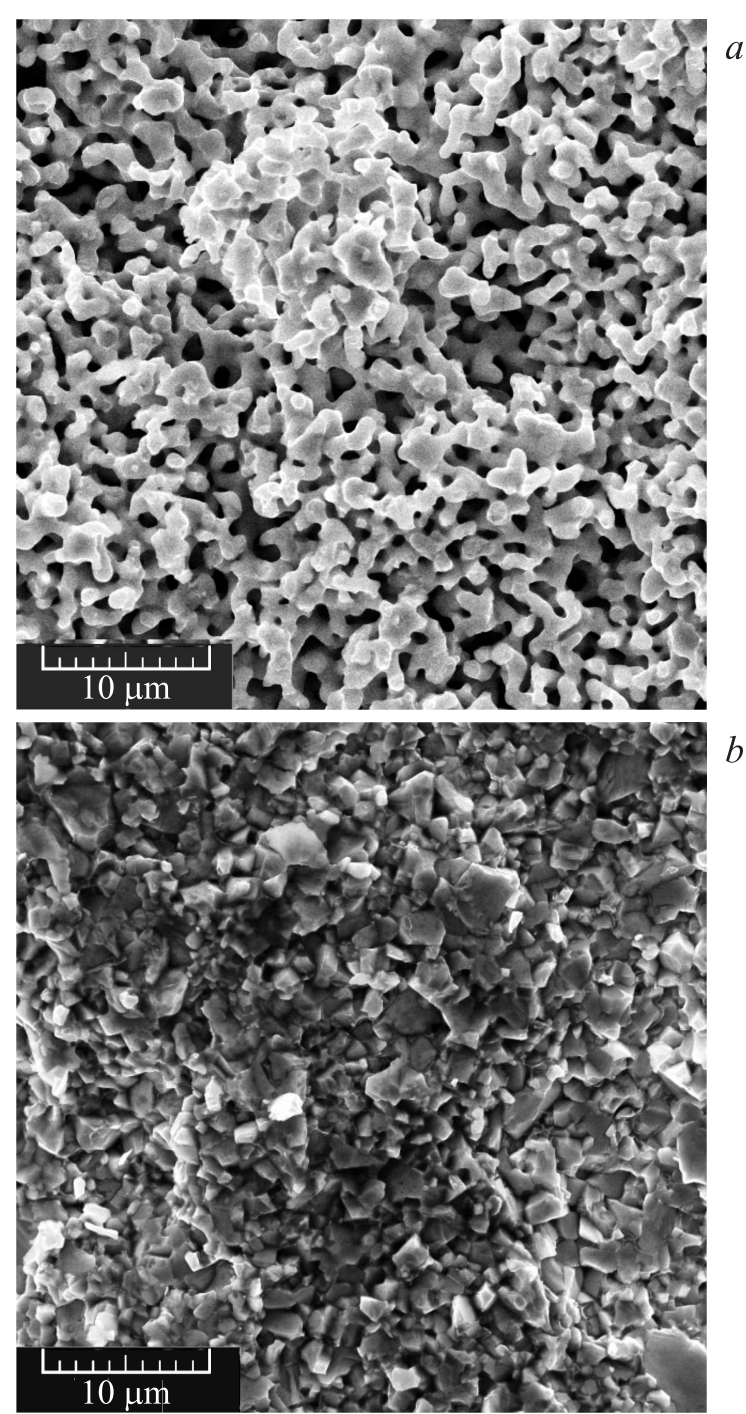

Pис. 2. Структура сплавов ВНЖК + ВК8: $a-$ ВНЖК $+40 \mathrm{wt} . \%$ ВК $8, b-$ ВНЖК +70 wt.\% ВК8. 
Результаты баллистических испытаний

\begin{tabular}{l|c|l|l|l|l|l|l|l|l}
\hline \multicolumn{1}{c|}{ Образец } & $\begin{array}{c}V_{0}, \\
\mathrm{~m} / \mathrm{s}\end{array}$ & $\begin{array}{c}\rho_{0 m}, \\
\mathrm{~g} / \mathrm{cm}^{3}\end{array}$ & $\begin{array}{c}c_{0}, \\
\mathrm{~m} / \mathrm{s}\end{array}$ & $\begin{array}{c}\rho_{0}, \\
\mathrm{~g} / \mathrm{cm}^{3}\end{array}$ & $\begin{array}{c}c_{0}, \\
\mathrm{~m} / \mathrm{s}\end{array}$ & $\xi, \%$ & $L / d$ & $\begin{array}{c}h, \\
\mathrm{~mm}\end{array}$ & $\Delta, \%$ \\
\hline ВНЖК+ 70 wt.\% BК8 & 2766 & 15.42 & 4500 & 10.29 & 3676 & 33.2 & 5.01 & 66.2 & 34.5 \\
ВНЖК+10 wt.\% TiWC & 2817 & 16.23 & 4200 & 11.72 & 3668 & 27.8 & 4.47 & 65.0 & 32.1 \\
ВНЖ-90 & 2817 & 17.1 & 4000 & 17.11 & 4000 & - & 3.19 & 49.2 &
\end{tabular}

ВНЖ-90 плотностью $17.1 \mathrm{~g} / \mathrm{cm}^{3}$. Из-за различной средней плотности ударники имеют разную длину $L$. Ввиду высокой твердости исходного образца материала ВНЖК + 70 wt.\% BК8 ударник был получен методом электроэрозионной резки. С применением баллистического комплекса [8] проведены динамические испытания соударения ударников со стальной преградой толщиной $87 \mathrm{~mm}$ при скорости $V_{0} \sim 2800 \mathrm{~m} / \mathrm{s}$. Ударники сохраняли свою целостность при разгоне в канале ствола, что подтверждает наличие упрочняющего эффекта при легировании пористого сплава высокопрочными компонентами. Результаты баллистических испытаний приведены в таблице и на рис. 3. Относительный объем пустот определялся по формуле

$$
\xi=\left(1-\rho_{0} / \rho_{m 0}\right) \cdot 100 \%,
$$

где $\rho_{m 0}$ - плотность материала матрицы (твердого компонента сплава). В таблице приведены значения скорости звука материала матрицы $c_{0 m}$ и пористого материала $c_{0}$.

Глубина кратера от ударника из пористого сплава ВНЖК +70 wt.\% ВК8 превышает глубину проникания ударника из монолитного сплава ВНЖ-90 на $\Delta=34.5 \%$.

Легирование пористого сплава ВНЖК карбидом титана-вольфрама TiWC при содержании последнего $10 \mathrm{wt} . \%$ также приводит к существенному повышению глубины проникания. Глубина кратера от ударника из сплава ВНЖК + $10 \mathrm{wt} . \%$ TiWC плотностью $\rho_{0}=11.72 \mathrm{~g} / \mathrm{cm}^{3}$, массой $m=30 \mathrm{~g}$ и диаметром $d=9 \mathrm{~mm}$ составляет $65.0 \mathrm{~mm}$ и превышает глубину проникания ударника из монолитного сплава ВНЖ-90 на $\Delta=32.1 \%$.

Более глубокое проникание ударников из высокопористого сплава ВНЖК, легированного карбидами вольфрама BК8 и TiWC, чем в случае

Письма в ЖТФ, 2017, том 43, вып. 17 


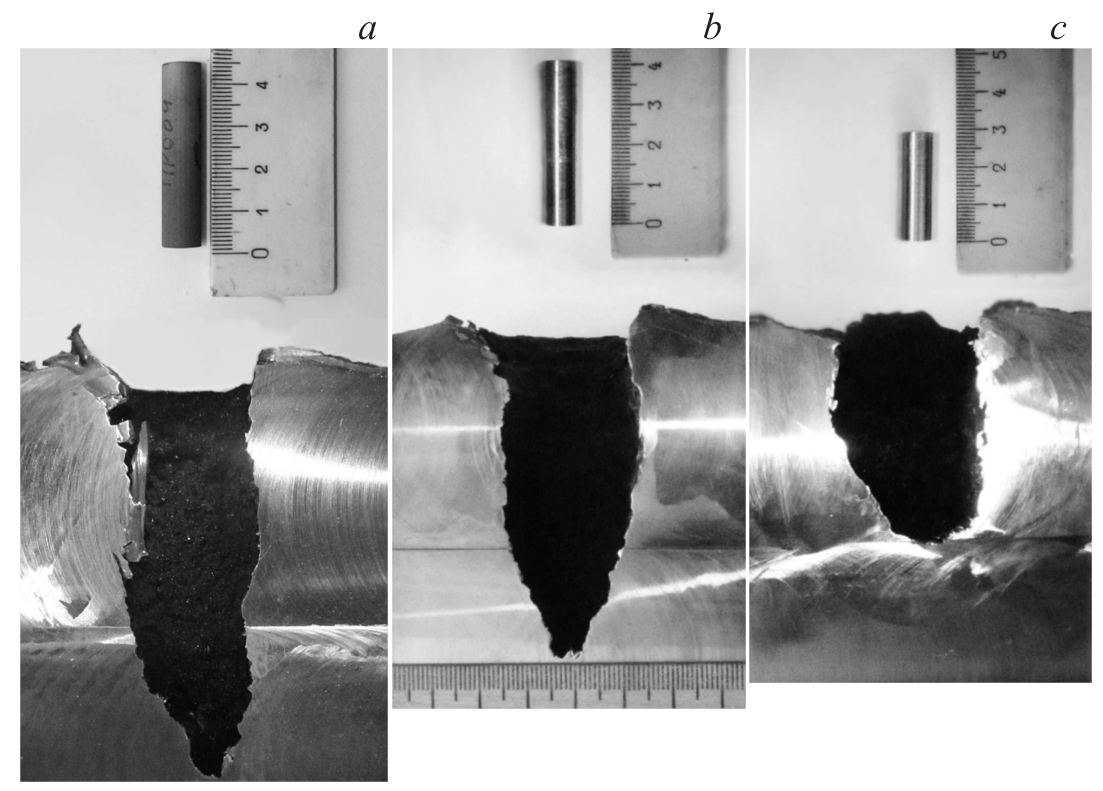

Рис. 3. Вид ударника и разрез кратера в стальной преграде после соударения: $a$ - ударник из сплава ВНЖК + 70wt.\% ВК8, $b-$ ударник из сплава ВНЖК + 10 wt.\% TiWC, $c$ - ударник из сплава ВНЖ-90.

равного по массе и диаметру монолитного ударника из сплава ВНЖ-90, объясняется следующими факторами. Во-первых, из-за низкой средней плотности ударник имеет бо́льшую длину по сравнению с монолитным. Во-вторых, высокопористый материал имеет более низкую скорость звука по сравнению с монолитным, и возмущение, вызванное ударом, слабее распространяется вверх по ударнику, при этом затухание скорости при проникании происходит значительно медленнее. В-третьих, материал преграды в зоне контакта взаимодействует с материалом матрицы, который содержит высокотвердые частицы карбидов, что создает дополнительный абразивный эффект.

Таким образом, разработаны новые композиционные материалы на основе высокопористых вольфрамовых сплавов, легированных карбидом вольфрама. Подтверждена основная тенденция повышения про-

Письма в ЖТФ, 2017, том 43, вып. 17 
никающей способности ударников из пористых материалов: ударники из пористых композиционных материалов ВНЖК $+10 \mathrm{wt} . \%$ TiWC и ВНЖК + 70 wt.\% ВК8 показали проникающую способность в стальные преграды, превышающую на 32-34\% таковую для монолитного массогабаритного аналога из сплава ВНЖ-90.

В работе использованы результаты, полученные в ходе выполнения проекта № 8.2.05.2017 в рамках программы „Научный фонд им. Д.И. Менделеева Томского государственного университета“ в 2017 г.

\section{Список литературы}

[1] Румянцев Б.В. // Письма в ЖТФ. 2016. Т. 42. В. 17. С. 87-95.

[2] Савельева Н.В., Баяндин Ю.В., Савиных А.С., Гаркушин Г.В., Ляпунова Е.А., Разоренов С.В., Наймарк О.Б. // Письма в ЖТФ. 2015. Т. 41. Вып. 12. С. 32 40.

[3] Афанасьева С.А., Белов Н.Н., Козорезов К.И., Табаченко А.Н., Хабибуллин М.В., Югов Н.Т. // ДАН. 1997. Т. 355. № 2. С. 192-195.

[4] Афанасьева С.А., Белов Н.Н., Крамшонков Е.Н., Хабибуллин М.В. // Исследования по баллистике и смежным вопросам механики: Сб. статей. Томск: Изд-во Том. ун-та, 1998. В. 2. С. 99-102.

[5] Табаченко А.Н., Бирюков Ю.А., Белов Н.Н., Югов Н.Т., Ищенко А.Н., Буркин В.В., АЯанасьева С.А., Мариунова Л.С., Югов А.А., Скосырский А.Б. // Из. вузов. Физика. 2011. Т. 54. № 10. С. 60-66.

[6] Афанасьева С.А., Белов Н.Н., Бирюков Ю.А., Буркин В.В., Ищенко А.Н., Мариунова Л.С., Табаченко А.Н., Хабибуллин М.В., Югов Н.Т. // Изв. вузов. Физика. 2012. Т. 55. № 11. С. 35-40.

[7] Ищенко А.Н., Абанасьева С.А., Белов Н.Н., Бирюков Ю.А., Буркин В.В., Рогаев К.С., Табаченко А.Н., Югов Н.T. // Четвертая Всерос. науч.-техн. конф. „Фундаментальные основы баллистического проектирования-2014“. СПб., Россия, 23-28 июня 2014. С. 152-155.

[8] Бураков В.А., Буркин В.В., Ищенко А.Н., Корольков Л.В., Степанов Е.Ю., Чупашев А.В., Агафонов С.В., Рогаев К.С. Экспериментальный баллистический комплекс. Патент на изобретение № 2591132 от 20 июня 2016 г.

Письма в ЖТФ, 2017, том 43, вып. 17 